\title{
Gendered Language in Recent Short Stories by Japanese Women, and in English Translation
}

\author{
Lucy Fraser \\ University of Queensland
}

\begin{abstract}
This article analyses five recent Japanese short stories written by women, with female first person narrators, and the English translations of these stories. I examine how the writers interact with the culturally loaded concept of gendered language to develop characters and themes. The strategies used by translators to render gendered styles into English are also discussed: case-by-case creative solutions appear most effective.

'Feminine' and other gendered styles are used to index social identity, to highlight the difference between the social and inner self, and different styles are mixed together for impact. Gendered styles, therefore, are of central importance and translators wishing to adhere closely to the source text should pay close attention to them.

All the narrators of the stories demonstrate an understanding of 'social sanction and taboo. Two accustom themselves to a socially acceptable future, another displays an uneasy attitude to language and convention, while others fall into stereotypes imposed on them or chastise themselves for inappropriate behaviour. The stories illustrate the way in which gendered language styles in Japanese can be manipulated, as both the writers and the characters they create deliberately use different styles for effect.
\end{abstract}

\section{Keywords}

women, gender, language, literature, translation

\section{Introduction $^{1}$}

The Japanese language is known for having different 'feminine' and 'masculine' styles,

1 Notes on Style and Citation: Discussions of short stories and page numbers cited refer to the Japanese source text unless otherwise marked. Translations following Japanese phrases in brackets are my own: they follow basic grammatical conventions but privilege meaning over style. Quotations from published translations are enclosed in quotation marks and followed by page numbers. 
.

which presents a versatile and fascinating device for writers to take advantage of. Furthermore, it may be argued that because English is not similarly demarcated in terms of gender, translating Japanese writing that employs these different gendered styles proves an intriguing challenge.

Onna kotoba-women's language-is a far more intricate issue than simply one of language style. In my analyses of three short stories by Japanese women, I examine how writers interact with the socially complex concept of gendered language to develop characters and themes. The narrators of these stories all seem to exhibit a degree of awareness of the 'social sanction and taboo' accorded to them as girls or women, and this awareness is often reflected in their different uses of gendered language. English does not appear to have a similar 'women's language' and I examine translators' responses to the challenge this cultural difference creates.

Gendered language styles such as onna kotoba can be of central importance to recent Japanese fiction, therefore translators wishing to adhere closely to their source text must pay careful attention to such language. My analyses of English translations of Japanese short stories show that translators, as can be expected, employ case-by-case solutions to this challenge. Creative methods are necessary as no single formula can be applied to the various difficulties that arise in conveying the nuances of gendered styles.

\section{Methodology}

The texts were selected according to the following criteria:

1. Written (in Japanese) by women: who have experienced the idea of Japanese 'women's language' first-hand in their lives.

2. Incorporates some use of onna kotoba or other gendered styles.

3. Short fiction: A wider range of writers are available in English translation in short fiction. It is also often simpler to summarise or describe.

4. First person female narrator: First person narratives give a greater scope for gendered language use and range of reactions/emotions.

5. Published recently: For the sake of further consistency, and for the legitimacy of comparison. The Japanese short stories and their English translations were published between 2000 and 2006.

6. Translated into English: In order that translation strategies can be analysed.

7. Variety of characters/themes: To explore different women's experiences (unfortunately no stories narrated by older female characters are included).

After a brief introduction to some of the issues of research into gender in 
literature, language and translation, I discuss three stories selected according to the criteria listed above ${ }^{2}$. I analyse the language styles and the themes in these stories: my approach is based on a background in literary studies, rather than being linguistic or translation-centred. I also examine the strategies employed by translators. Analyses are based on the texts and the translated texts themselves: because the stories were published and translated relatively recently, and because many of these authors are not widely translated or read in English, there was not a large amount of criticism available. However, any academic criticism of these texts has been used where possible.

This article, then, is an interdisciplinary one, incorporating aspects of Literary Studies, Translation Studies, Gender Studies, and Sociolinguistics.

\section{Rationale}

This research brings to the fore selected works by current female Japanese writers, the majority of whom have not been widely published or studied in English. All the writers discussed have won or been nominated for high profile literary prizes, or have received a large amount of media attention in Japan. The stories deal with issues of contemporary Japanese society. Relationships, the process of growing up, working life, and families are some of the topics that are covered; these issues, of course, are all relevant to the Englishspeaking world and they provide an insight into some of the different experiences of Japanese women today. The stories make accessible diverse and three-dimensional portrayals of Japanese girls and women, and combat conventional Western images of the mysterious oriental female.

Similarly, I am concerned with exploring a variety of images of women, and with the complicated issues of gender in language and literature. I question stereotypes of Japanese women and 'women's language', and examine a diversity of femininities.

This research also addresses a challenge that is often faced by translators working from Japanese to English. It discusses various practical solutions translators have employed to translate gendered language styles, but more importantly, it seeks to highlight the centrality of onna kotoba and other gendered styles to the narratives. It is a reminder that these particular uses of language can be of the utmost significance to the story and should therefore be translated with great consideration.

Additionally, the research contributes to a growing and interdisciplinary field

2 All three translations were published in Inside: Japanese Women by Japanese Women, commendable in its aim to 'reflect the experiences of a wide diversity of Japanese women' (Ozeki 'Foreword' p. 9). 
.n.m.n. of

of gender-based analysis of translations. Santaemilia encourages more attention to the issue of gender in translation, asserting that 'we must recognize the immense capabilities of gender/sex and translation studies for generating debates of a fundamentally cross-disciplinary nature within more egalitarian parameters' ${ }^{3}$. As Baumgarten points out, the kind of 'contrastive linguistic analysis' such as I undertake is 'a prime way of investigating the parallel or as it were "co-occurring" ways and strategies of constructing social reality in texts across cultures'4. The value of such an investigation, in fact, lies in its social implications.

\section{Background}

The language of Japanese women has been variously described by linguists as 'verbose, repetitive, conservative, concrete, trivial, soft and emotional, polite, pure and syntactically loose'5. While some of the supposed features of 'women's language' are discussed in relation to the short stories, my purpose is not to argue that men and women use Japanese differently. Rather I adhere to Inoue's construction of onna kotoba as 'a socially powerful truth' $^{6}$, what Washi describes as an 'artificial construct'7. As Inoue argues, the concept of women's language is experienced in the everyday life of many Japanese people, most commonly through the 'imaginary voices' of media such as 'novels, movies, TV shows, drama scripts, animation, and computer games's.

How do writers, who have personally experienced such expectations of women and women's language, deal with these 'imaginary voices' in their own fictional texts? My analysis depends on Butler's theorisation of gender as 'a constructed identity, a performative accomplishment ${ }^{\text {' }}$. Rather than being natural, or an inscribed social construct, gender is acted out by the individual. However, as Butler points out, the acts that constitute gender are motivated by social factors: 'what is called gender identity is a performative accomplishment compelled by social sanction and taboo ${ }^{10}$. Writers, then, in both dialogue and first-person narration, may be said to 'perform' character and gender through the medium of language, even as that character herself performs gender within the story. These doubled performances are then re-enacted in another language, performed a third time by the translator.

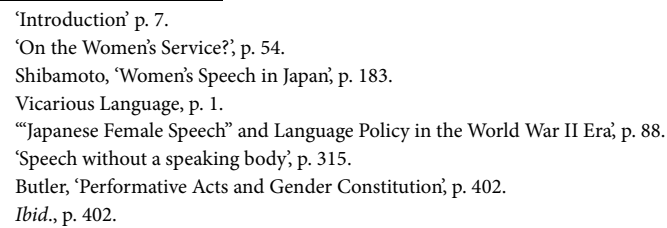


This third performance, the translation of onna kotoba and other gendered language into English, may be challenging as, I argue, no similar concept of a women's language exists in English. There are various stereotypes concerning the different communication styles of male and female English speakers: there is the idea that women speak more than men, negative labels for women's talk such as 'bitchy', and the belief that women are more polite than men ${ }^{11}$. However, these differences cannot be introduced into a translation to convey 'femininity' without creating significant deviations from the source text.

Of course, this is only one of the many challenges facing translators of fiction, and that the context and aims of a translation should be taken into account when it is analysed. As Bassnett-McGuire explains, one of the goals of translation theorists is 'to reach an understanding of the processes undertaken in the act of translation and, not, as is so commonly misunderstood, to provide a set of norms for effecting the perfect translation'12. Similarly, I do not attempt to judge these translations in terms of their 'success', but instead use them as a means to examine a particular aspect of Japanese writing. The study of translation is a varied and complex field. Of the many possible approaches, this paper is to some extent aligned with feminist translation theories, and their aim to translate works written by women in order to develop a body of work and discover a history of women's literature. The translations I examine certainly contribute to this project.

\section{Kotoba de setsumei dekinai}

Sentence Final Particles, Vocabularies and Youth Language In 'Miruku' by Daidō Tamaki, translated as 'Milk' by Louise Heal.

Language is both an alienating and an embracing power in Daidō Tamaki's 'Milk'. The school student narrator Komugi uses wakamono kotoba or 'youth language' fluently, obviously identifying herself as a teenaged girl as well as belonging to a particular group of friends. On the other hand, Komugi seems uncomfortable with the sexuality of her peers, and unable to express her own sexuality in language. Her attitude to language, sometimes comfortable and sometimes uneasy, reflects her awareness of the 'social sanction and taboo' accorded to her as a teenaged girl. Komugi uses a particular

11 See, for example, work by sociolinguists Jennifer Coates or Janet Holmes. Additionally, these stereotypes are perhaps most apparent in popular self-help books for heterosexual couples such as John Gray's Men Are From Mars, Women Are From Venus (HarperCollins 1992), or Deborah Tannen's You Just Don't Understand (Ballantine 1991).

12 Translation Studies, p. 37. 
.

speech style to fit in with her friends, but she cannot find the language to express her socially inappropriate or discomforting feelings and experiences.

Komugi has a distinctly individual voice that is created through a combination of several features. Most predominantly, she uses wakamono kotoba ${ }^{13}$, slang words such as maji de (11) (really), dasai (12, 15) (uncool), iketeru (17) (attractive/cool), bibitta (6) (got scared), uzai (25) (annoying), and mitai na (11) (like/similar to). The style is casual and conversational, and words are written as they are pronounced, such as wakannai (10) instead of wakaranai (I don't understand), and konaida (24) for kono aida (recently). There is also the lengthening of sounds as seen in da yo naa (19) (isn't it). While this extremely casual language and repeated use of particle na as in da yo na (7) seems slightly masculine, it should be noted that its use by girls and women is considered to be becoming more common ${ }^{14}$. The use of the girlish atashi for 'I', on the other hand, makes Komugi seem somewhat deliberately cute when it is used together with the plain and masculine words.

Komugi also uses a mixture of sentence final particles that are considered typically masculine and feminine. Sentence-final particles (SFPs) convey the speaker's feelings or intent: there are those traditionally associated with masculine language: $z o$, $z e, s a, n a$, those associated with feminine language: wa, kashira, mono, and those used by both males and females: yo, ne, no. Some of the particles in the third category are not necessarily neutral, and are said to be used differently by males and females.

Komugi's typically 'feminine' uses of language include frequent use of $n e$ as in namiko wa yamenai ne (8) (Namiko won't quit), use of mon (23) as a shortened form of mono, and use of particle wa (6). Komugi narrates the story in the same way she speaks with her friends. Her personal style is characterized by brief statements with numerous pauses: Daidō uses a great number of short sentences and commas, which create a blunt, almost staccato effect: iranai mono wa, kirisuteru (15) (discard anything unneeded), or again in ie ni ite ii nara, ite yaru. deteku riyū nai mon. oya to hanareru no, kokorobosoi mon (16) (if it is ok to be at home, I will be at home. I have no reason to leave. I would be lonely apart from my parents). This may be part of Komugi's attempt at a cool and unruffled persona $(25,30)$ or point to her troubled relationship with language.

Komugi's fluent use of the 'in' speech seems to give her a sense of belonging within her group of friends; its function is similar to the matching cardigans that the

13 Described in Maynard's Expressive Japanese.

14 Reports of the increasing use of 'masculine' styles by girls should be considered in the context of the long tradition of condemnation of females' use of unfeminine language: see Inoue (Vicarious Language p. 163). However, the idea that gender differences in Japanese are becoming less pronounced is a common one. 
girls wear in keeping with the latest craze. She is also, however, isolated by language: it is insufficient to truly connect with other people. Although the reader is addressed in a candid voice, the surrounding characters are not privileged with such honesty. The text is scattered with Komugi's vague inability to put her real thoughts or desires into words: she does not want to burden her friend with serious conversations (10), she does not tell her parents what she really wants (18), she does not talk about her family because it will bore her friends (20), and she cannot explain in words what her life is like to anyone (30).

This inability to speak about herself seems to be closely linked to her experience of sexuality as an aggressive and intimidating force. She is frightened by her overtly sexual friend Namiko, who has muda ni okki na mune (21) (unnecessarily large breasts) and thinks boys' 'things' are cute (26). Namiko, unlike Komugi, is good at talking about sex ${ }^{15}$; Komugi dislikes hearing about it so much that she cannot even nod during these conversations (33). It is the sheer physicality that seems to overwhelm Komugi, and she envies the remote beauty of her friend Akina who looks far away in photos (6). Her boyfriend, Toshima Ryūji, is also aggressively sexual, bragging about sex and describing it in crude, blunt terms (32). Komugi's reaction to their encounters is described fairly negatively, in physical terms, as in her first kiss: nama attakai hen na kanshoku na no ni, atashi wa nandemo nai to iu fü na kao o tsukutta. hayaku uchi ni kaeritakatta kara $n a$ (24-5) (it felt warm and strange, but I tried to look like it was nothing. Because I wanted to go home soon). When Komugi kisses Ryūji's neck and he ejaculates, she pulls back and describes the smell, wondering if Ryūji's mother cleans up the tissues he uses to wipe himself (29). She likens his ejaculation to milk: the title of the story, then, also emphasizes the messy physicality of sexual experience. Interestingly, Komugi links sexuality with domesticity again when she compares her vagina to a clam and thinks it would probably look tasty on the dinner table (35). Perhaps this is an attempt to assimilate these new experiences with the familiar domestic world.

Onna kotoba is in fact often linked with the domestic world, described as associated with the 'household domain.' ${ }^{16}$ 'Men's' words are considered to be more plain or vulgar and 'women's' more standard or polite. For example, meshi versus gohan for meal/cooked rice $^{17}$. Other expressions described as exclusive to female speech include 'the exclamative iyaa "wow"'; other words such as suteki (nice) and kawaii (cute) are associated with femininity. ${ }^{18}$ Another apparent difference in male and female speech is the frequency of use of certain words or expressions. Farnsley states that women 'frequently interject adjectival exclamations into their speech (ii wa - "that's good", or

\footnotetext{
15 Frederick notes that this kind of pairing of 'a shy, insecure girl and a spunky friend' has a history in girls' fiction and 'remains a popular combination' in current shojō manga (girls' comic books) and animated programs for girls ('Not That Innocent: Yoshiya Nobuko’s Good Girls', p. 69).

16 Shibamoto, 'The Womanly Woman', p. 28.

17 Ibid., p. 28; Ide, 'Japanese Sociolinguistics: Politeness and Women's Language', p. 379.

18 Maynard, Expressive Japanese, p. 24.
} 
.

omoshiroi ne - "interesting")', adding that this may be a deliberate tactic to make speech sound more emotional, or relate to 'flirtation techniques.' ${ }^{19}$

Komugi, however, does not have such a strong technical control over language. Despite her lack of interest, she eventually promises to have sex with Ryūji because she cannot find the vocabulary to refuse him (25). Komugi may be unable to speak about sexuality because no appropriate language is available to her. Tomioka Taeko argues that women's language cannot accommodate sexual topics: 'when it comes to sex, daily speech...uses the language of pornographic fiction or similar reading material...It is a kind of "men's language". ${ }^{20}$

Komugi may feel uncomfortable with the language used to describe sexual matters, but her friend Namiko certainly does not. Perhaps Komugi feels isolated from sexual and gender norms, so she cannot express herself in the mainstream language that she shares with her friends. There are some hints that she does not conform to the feminine school girl image: firstly, she is not interested in owning a mobile phone, the must-have accessory ${ }^{21}$, and she is annoyed when her parents buy her a (feminine) silverpink one (27). Secondly, she offhandedly decides she might go for the 'pants look' rather than skirts or dresses in high school (19).

In her translation of 'Milk', Heal deals very well with the contradiction of Komugi's confident use of her teen-speak and her inability to talk about her feelings and sexuality. Heal translates Komugi's wakamono kotoba into American teenager's slang, using words such as 'guy' $(15,18,28)$, 'huh?' (25), 'gross' $(31,42)$ 'lame' (32) 'suck' (38) 'big deal' $(20,33)$, as well as using 'like' as a discourse marker or instead of 'said' $(17,21,33)$. Use of mildly rough language such as 'crap' (22), 'pissed off' (29) and 'wetting themselves' (33) reflects the slightly masculine language in the Japanese. Other phrases that Heal chooses have their origins in the speech of the Californian 'Valley Girl', who is known as a 'superficial teenage girl', 'shopping-obsessed and airheaded'.22 Although words such as 'totally' $(15,23,37)$, 'seriously' $(17,21,27)$ 'max' $(24)$, 'whatever' $(28,31)$, 'awesome' $(18$, $28,37)$ and 'barf' (30) are fairly widespread today, they are still associated with Valley Girl, and therefore an effective means of translating the feminine atashi and the school girl slang that Komugi uses. This particular slang has the advantage of being widely recognized. Because it originated in the home of Hollywood, the 'Valley Girl' style has had international exposure in many movies ${ }^{23}$ and it is spreading: mature Australian adults, for example, are increasingly using the emphasized 'sooo' (Heal uses this p 16,

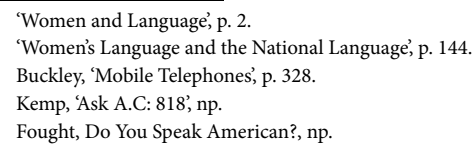


25) and other American youth slang. ${ }^{24}$ Heal's appropriation of this style is therefore very effective in conveying the gendered styles of the Japanese source text. However, it should be noted that this strategy is not broadly applicable: not all texts are written in such an identifiable style, and not all styles have such a widely recognised English equivalent.

This translation, then, is based on a style 'equivalent' to that used in the source text: however, this does not seem to be the kind of equivalence that translation theorist Goddard criticizes, wherein 'certain cultural traces and also certain self-reflexive elements are eliminated from the text so that the translated text is deprived of its foundation in events. ${ }^{25}$ Goddard emphasizes the role of the translator as 'decoder' and 're-encoder' rather than one simply who domesticates something foreign, suggesting that 'each language classifies and organizes the world and the translator creatively intervenes in such instances. ${ }^{26}$ Heal's adoption of existing American slang does not erase the 'cultural traces' of the source text: rather it works to depict the girlish culture of the narrator. Also, while Heal's translation style is certainly not 'foreignizing', she does attempt to convey some of the Japanese features of the text such as oden (16) and the significance of being addressed 'with the respectful san' (30). In fact, Heal uses a type of 'equivalence' to produce an English translation that communicates the uniquely Japanese aspects of the source text, rather than 'eliminating' them. Perhaps this is the creative re-encoding that Goddard recommends.

\section{Watashi no kuchibiru wa naze ka}

Keigo and Rough Language in 'Musuko no kuchibiru' by Uchida Shungiku, Translated as 'My Son's Lips' by Cathy Layne.

Uchida Shungiku's Musuko no kuchibiru (My son's lips) is narrated by a working mother who has a strange encounter with an irritating taxi-driver. The story is constructed around the narrator's knowledge of 'social sanction and taboo' as the reader hears her socially appropriate dialogue as well as her (repressed) informal and often irritated inner voice. The narrator's lifestyle, which involves juggling work, parenting, and running a household, is mirrored when she must juggle two conversations at once (with the taxidriver and with her son) and when she must hold her baby daughter at the same time as opening a bottle of drinking yoghurt for her son.

The narrator refers to herself neutrally as watashi but uses girlish atashi when

\footnotetext{
Gare, 'Airheads', np.

'Theorizing Feminist Discourse/Translation', p. 91.

Ibid., p. 91.
} 
.

speaking to her husband. For the most part of the story, there is a great difference between the way this character speaks out loud and her inner monologue. The bulk of the dialogue is made up of the speech of other characters, and when she does speak it is mostly with polite listening noises, or else motherly admonitions such as arigatō wa? (7) (say thank you) and shizuka ni shite nasai (10) (be quiet please). Much 'motherese'27, including the sentence above, is based on honorific language, or keigo. Keigo is a distinct mode of language that expresses politeness. Bikago, discussed in the next section, is one aspect that 'beautifies' words. Women are said to use all types of honorifics more frequently than men..$^{28}$

The narrator's polite speech in this story is a mixture of different levels of formality. She uses some keigo, for example, at the awkward moment when she is invited to the taxi driver's house and prompted by him to give his wife advice on drying clothes: pajama o, kansōki ni ... irenai de, hoshite, itadakitai to no koto desu (17) (would like to receive the favour of [humbling form] you not putting the pyjamas in the dryer, and hanging them out to dry instead). In other instances she uses simpler polite language such as omutsu, kaete mo ii deshō ka (15) (do you mind if I change her nappy?). The narrator's politeness, motherly language, and relative silence represent the 'appropriate' behaviour expected of her as a woman and a mother; the fact that she is acting out this role is highlighted by the cynical, humorous, and often angry observation of events of her inner monologue that the reader is privy to.

More frequent use of profanities and vulgar language is said to be a feature of 'masculine' speech. Deprecatory verb forms, different word endings and rough words and expressions are all listed as belonging to the 'masculine' style. ${ }^{29}$ Changing certain words that end in oi or $i$ sounds to end in a long ee sound-'reduction forms'-are also listed as a feature of male language. ${ }^{30}$

The narrator of Musuko no kuchibiru expresses her anger and frustration beneath her polite exterior with slightly rough/informal language in her inner monologue. When she describes her irritation at having to listen to the taxi-driver talk, she uses the verb [kiite]yaru (8) for 'to give [the favour of listening]' which is usually used when speaking about animals or inferiors, rather than the respectful ageru. She also merges the phrase yaranakereba naranai (must do/give) into a shorter, slangy version. She imagines using a rougher (nevertheless feminine) form of 'you', anta, to angrily address her subordinates at work: anta wa, watashi no musuko janai (29) (you're not my son). Another imagined

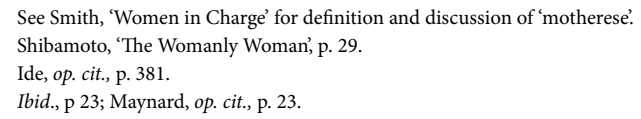


irritated comment to a subordinate is emphasised with the masculine sentence final particle zo: shōgakkō no sensei mo damasenai zo (30) (you couldn't even fool a primary school teacher with that). Other shortened words, phrases, and short or incomplete sentences also indicate her frustration, as in damarya shinai (9) (he won't shut up), shortened from damari wa shinai, as well as the incomplete nan to meiwaku na (9) (what a pain), and the blunt dare mo hondai ni furenai (16) (no-one gets to the point).

Outwardly, the narrator conforms to the expectations of others with polite language, 'motherese', and noises to signal she is listening; it is conforming to images that others have of her, however, that seems to cause her problems. As Butler would explain it, the narrator comes to believe her own performance of gender. ${ }^{31}$ When she wonders why she allowed a taxi driver to waste her time with a long detour, she realises that she herself had come to accept his assumptions about her: nan da ka nee, jibun wa honto wa hima de hima de shō ga nai, tāikutsu na shufu datta no kamo shirenai-tte omochatta mono nee, tochü de (28) (I think I really believed I had nothing but free time, I started to think I really was a very bored housewife). Similarly, kissing one of the young men working under her may imply that she has given up fighting the opinions of others. She feels annoyed that as soon as they find out that she has a young son, these young male subordinates jibun ni atehametagaru (29) (tend to apply that to themselves) and act spoilt or sensitive. The narrator fears that the attitudes of these young men are somehow her fault, and that she will raise a son who will give her the same sulky looks that they do: ano iya na kao o suru yō na otoko ni, musuko mo sodatteiku yō na ki ni naru (31). In the end, she does fall into the mother-son pattern with her staff: when she gets into (what she suspects is) the same taxi she rode earlier with her son, and kisses her new subordinate, his lips are soft like a child's cheek. The title 'My Son's Lips' is explained.

Although this story is not particularly confronting, the hint of incest in this act, highlighted by the title, is more significant in the context of Uchida's other work, including a novel titled Fazaa fakkaa (Father Fucker). Yokota-Murakami describes the author's 'persistent interest in abnormal kinds of sexuality'32, concluding that Uchida's textual strategy 'foregrounds conflicting principles: the scandalous and the mundane, the marginal and the ordinary, and the subverting and the conventional ${ }^{33}$. Orbaugh writes that incest is a common theme in stories by Japanese women published between 1960 and 1975, and that these stories are often 'oddly lacking in any overt dichotomization of "victim" and "victimizer"' ${ }^{34}$ Orbaugh points out that such 'socially disruptive behaviour'35 can challenge conventional understandings of gender and the binary oppositions they

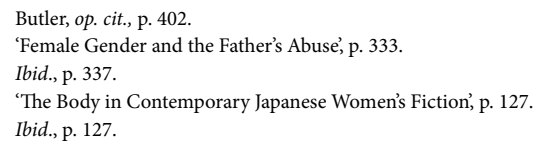


.

entail $^{36}$. Perhaps even Uchida's hints at incest, conflicted with conversations about laundry chores and sewing, go some way to creating the same challenge.

There is something else significant about the kiss that closes the story: watashi describes it as an event that she had no control over. She is fully intending to tell the young man she is fine, but instead finds that watashi no kuchibiru wa, naze ka kare no kuchibiru no hō e chikatzuite iki, sono mama sore ni fureteshimatta (32) (my lips, for some reason, went closer to his lips, and brushed against them). In kissing this man she has succumbed to a definition of herself as 'motherly' and, importantly, she has lost control of her lips in a way that is reminiscent of her inability to say 'no' or 'shut up' to the taxi-driver.

Translator Cathy Layne deals with the gap between dialogue and narration well, adopting polite formulas like 'Beg your pardon?' (103) and 'I'm sorry?' (105) for speech, and a blunt vernacular for watashi's voice, as in 'I want to talk to my own kid, not listen to someone else blather on about theirs' (103). Although the complexities of the mixture of keigo and polite language used by the narrator do not exist in English, politeness is similarly associated with femininity. ${ }^{37}$ The 'feminine' aspects of the language in this particular story, then, are relatively easy to re-perform in translation.

\section{Hanabira ga adappoku warau}

Kango and Bikago in 'Museiran' by Hasegawa Junko, Translated as 'The Unfertilized Egg' by Philip Price.

Hasegawa Junko's Museiran (unfertilised egg) is narrated by 36-year-old office worker, Moriko, who is having an affair with her married boss, Aono. Hasegawa combines a range of language styles to produce Moriko's rich and playful style. Moriko negotiates her desire to become pregnant, her loneliness, and her frustrating encounters with others through different feminine, masculine, old-fashioned and informal language. Price's translation cleverly conveys the unique wordplay but can not always reproduce the nuances of femininity.

Ueda writes that the mistress in Japanese literature is traditionally portrayed as 'a flower in the shade', a forlorn beauty 'touched by sadness and loneliness. ${ }^{38}$ Moriko is certainly lonely, and interestingly describes her own vulva as a plant in the shade: nan'yō

\footnotetext{
Ibid., p. 134.

Cameron and Kulick, Language and Sexuality, p. 53.

The Mother of Dreams, p. 12.
} 
no kotō, hi no sasanu shitchi ni ikitzuku sekai saidai no inkashokubutsu (116) (the world's largest cryptogam/hidden plant growing on damp ground without sunlight on a remote South Pacific island). Although the story is about her wanting to become pregnant, her loneliness does not seem to manifest as envy of Aono's perfect family or a desire for more friends. Rather she wants someone to acknowledge her existence and know her closely: she describes her apartment as nureta mama no kuroi kabi ga kobiritsuita haisuikan ga nanbon mo wattateiru, dare mo tōranai dokoka no machi no biru no sukima ni niteiru (111) (like the space between buildings in a town somewhere, crossed by black mouldy sewerage pipes, where nobody goes), and she points out that aonosan wa watashi no heya ga kitanai no mo shiranai shi, furoba de utau uta mo shiranai. watashi wa aonosan ga neoki no toki no kusai iki mo shiranai shi, neguse no kami o waratta koto mo nai (117) (Aono doesn't know that my room is messy or the songs I sing in the bath. I have never smelt his bad breath or laughed at his hair when he wakes up).

Hasegawa's story is certainly not a romanticised, 'tragic beauty' rendering of Moriko's role as a (rejected) mistress. Moriko is a messy, interesting character who nevertheless acknowledges 'social sanction and taboo' when she chastises herself for inappropriate behaviour for her age. She comments that ii otona ga ōru nante suru mon janai (107) (good adults don't do things like stay out all night), and describes her chaotic lifestyle as shibuya no puchi iede no kogyaru mitai (113) (like a naughty Shibuya girl who has run away from home).

Moriko's vocabulary, as might be expected, is much more sophisticated than that of the teenaged protagonist of 'Milk', and in fact is the most complex of all the narrators discussed here. There is an abundance of kanji (Chinese characters) and kango, which are often seen as more educated and sophisticated, and have a long history of belonging to the masculine sphere. Kango are words made up of Chinese characters, with a pronunciation originating in Chinese, as opposed to 'native Japanese' words, wago. There is evidence that kango words are still used less frequently by women ${ }^{39}$, who have been encouraged to use soft, feminine speech. ${ }^{40}$

Moriko's play on kanji and kango makes her seem clever, and prevents her from becoming an 'other woman' defined only by her sensual beauty. Her preference for kango over hiragana words lends formality to her voice: she uses sobo ga mada zonmei no jibun (114) where another might use something more friendly like obaachan ga mada ikiteita toki for 'when my grandmother was still alive'. Words that are just as often left in hiragana are given in kanji, including mabuta (107) (eyelid), and hazu (140) (ought to).

Shibamoto, 'The Womanly Woman', p. 29; Shibamoto, 'Women's Speech in Japan', pp. 56-57.

40 Abe, 'Stereotype to Context', p. 654. 
incus is

The title of the story, Museiran, is also a scientific kango word. Another interesting use of kango is 隠花植物 $(116,126)$ (inkashokubutsu), a scientific word meaning 'cryptogam', a dated botanical term for 'a plant with no true flowers or seeds, such as a...moss... alga, or fungus. ${ }^{41}$ This resonates with Moriko's likening her apartment to the space between mouldy sewerage pipes (111), and her likening her genitals to a plant growing on damp, shady ground (116). The characters that comprise this scientific word are not obscure and also mean 'hidden flower plant' when read separately. Price does not use the word 'cryptogam', which would not be as self-explanatory in English, choosing to limit his translation to another of the scientific-sounding terms (written in katakana), 'rafflesia' (181). Moriko uses inkashokubutsu rafureshia (116) to describe her own vulva. The rafflesia is known as the largest flower in the world: it has rubbery reddish-brown petals and smells like carrion, which attracts the flies that pollinate $\mathrm{it}^{42}$; perhaps this is a comment on Moriko's sexual partners as well as her attitude to her genitals. The neat combination of four-character compound followed by katakana word connotes precise, scientific knowledge, while being easily understood by Japanese readers as 'hidden flower plant', and it describes a damp fungus as well as an enormous foul-smelling flower that attracts flies.

Moriko also favours kanji compound phrases. ここは私の污部屋也 (111) (koko wa watashi no oheya nari) seems to be one of her own, with the four-kanji compound as well as the old-fashioned character for 'is', nari, lending an air of importance. It is also a play on words: the first character means 'dirty' but is read as $o$, formalizing the word for 'room' into oheya. This pun is, in fact, extremely sharp, as words formalized with the 'o' prefix are known as 'beautified', or bikago, and are associated with stereotypically feminine, polite language. ${ }^{43}$ In other words, Moriko uses the character for 'dirty' to 'beautify' her room. Price cleverly translates this phrase using both grandiose and plain language, with 'Behold the trash heap of my apartment' (176).

Moriko describes herself with another kanji combination, ださくてだらし ない妄想淫夢女 (113-114) (dasakute darashinai mōsōinmu onna - uncool, vulgar, delusional, dirty dream woman). Such a varied description cannot be so succinct in English, so Price picks up on the alliteration of dasakute darashinai and turns it neatly into 'a sad, sleazy slut' (179). There is also a play on the phrase 無銭飲食 (musen'inshoku - skip out on paying for drinks and food), which is twisted into 無銭淫食 (125) (musen'inshoku - skip out on having sex and paying for food). The waga prefix is used repeatedly, creating another contrast between the grandiose and the ordinary or the private. Commonly seen in words like wagaya (my/our own house) and wagasha (this/

\footnotetext{
Soanes and Stevenson, The Concise Oxford English Dictionary [online].

Ibid.

Okamoto, 'Ideology in Linguistic Practice and Analysis', p. 40.
} 
my company) it has connotations of formality as well as the importance of family, team, or close belonging, which makes it almost empowering or proud when Moriko uses it to create wagaki (116) (my own genitals) and wagatamago (135) (my own eggs).

Moriko also often speaks in quite a 'masculine' way, which makes her appear angry and cynical rather than a sad beauty. She uses vulgar words like chikushō (113, 134), 'masculine' sentence final particles as in da zo (112) and nozokikomu na (138) (don't peer); she addresses her own genitals with omae (116), a rough word for 'you', and shortens naranai to naran (119). Price translates the rough aspect of her voice well, sprinkling the text with swearwords: men, for example, are often referred to as 'bastard' $(178,179,188)$ and Moriko's exclamation ha? (121) becomes 'What the fuck...?' (185).

There is also, however, frequent use of the 'feminine' sentence final particle $w a$, as well as some other feminine language, and the contexts in which Moriko uses these feminine styles are significant, as well as difficult to translate. Inoue points out that Japanese 'women's language' is heard most commonly 'not so much from living bodies of Japanese women, as from imaginary voices' ${ }^{44}$ : in this story, Moriko attributes women's language to imagined or remembered voices, which highlights her alienation from 'normal' femininity. She imagines the gurabia-jō (model lady) in a magazine speaking to her in formal, feminine style: okage de kochira mo nemidaremashita wa (110) (my sleep was also disturbed because of you). Price does not convey the femininity or formality with his translation: 'she glares up at me accusingly, as if it were my fault that she didn't sleep properly either' (176). Moriko also imagines women satisfied in stable relationships saying sekkusu-tte mendokusai waa (113) (sex is too much effort), which Price translates simply as 'say they can't be bothered with sex' (178). Price does convey some of the femininity of a conversation Moriko remembers having with her mother and grandmother: tanoshimi da wa nee (114) (that is something to look forward to, isn't it?), which he translates with an adjective thought to be used more by women: 'wouldn't it be wonderful?' (179). In each of these cases Moriko attributes feminine language to an imagined or remembered voice, which emphasizes her feeling of having failed to be properly feminine: she is not a classy magazine model, nor is she a woman properly loved, and she does not have children as her grandmother and mother did. As Price is not always able to convey the feminine nuances of these voices, the effect is not so apparent in his translation.

Moriko also uses feminine wa when she nostalgically speaks about 'first time' movies, echoing the gentle, romantic nature of the movies as well as the naïve young Moriko who was watching them. Her saikin nai wa nee (119) (they don't exist these

44 'Speech without a speaking body', p. 315. 
.

days) is translated by Price as 'they never make those first time movies anymore, do they?' (184), which is slightly softened by 'do they'. Moriko also comments hontō ni yume no nai yo no naka ni natta mon da wa (120) (it really has become a world without dreams), and Philip's translation emphasizes the sad, wistful, side of her remark with 'God, nobody dreams anymore' (184).

Moriko also uses particle wa in particularly un-ladylike situations as an ironic reminder of her unrefined behaviour. She describes climbing stairs returning home from all-night drinking as sasuga ni kitsui wa (109). Price translates this as the stairs feel extra steep this morning' (175), but perhaps a more prim expression could have a similar effect to the Japanese of highlighting the un-ladylike situation. When Mikami offers Moriko sex then leaves her with the bar tab, she makes one sarcastically feminine comment: bushido ni han suru wa (125) (that is not the way of samurai). She uses the noble image of samurai to condemn Mikami's petty behaviour, and also speaks about it in 'ladylike' language, highlighting her anger at his un-gentlemanly behaviour even more. Price's translation, 'not exactly the way of the samurai' (188) captures the sarcasm but the femininity is lost.

Price translates Moriko's wordplay very cleverly, but does not convey the femininity of certain expressions. This does not seem to be due to an urge to remove any feeling of 'foreignness' from the text: it likely indicates the difficulty of putting these phrases into English, or perhaps Price does not consider them important to the story. In any case, Price does make it clear that the narrator is female. The writing also abounds in images of female sexuality like shiny eggs and large damp flowers, so if these are taken in conjunction with the often coarse and sarcastic language in the English translation, it may be argued that the contrasts of Hasegawa's story are nevertheless conveyed.

\section{Conclusion}

This article has suggested that onna kotoba and other gendered language styles provide a fascinating tool for writers. Onna kotoba in particular is inscribed with a variety of cultural meanings: many speakers are aware of its various associations and deliberately manipulate them for their own expressive purposes. Japanese women writers use language to 'perform' the gender of their characters, just as those characters themselves perform gender within these stories. Gender is then re-performed in the medium of another language by the translator. Gendered language styles were examined in the context of specific features of onna kotoba through the analysis of three short stories written by Japanese women. 
Daidō Tamaki's Miruku is narrated in the slangy speech of a teenaged girl who is disturbed by the aggressive sexuality of her boyfriend and by her changing friendships. The girl uses language to fit in, but it also alienates her because she cannot express her feelings and experiences in words.

The narrator of Uchida Shungiku's Musuko no kuchibiru is a working mother who speaks with polite/motherly language: other characters assume she is a 'bored housewife, while the reader hears her angry, cynical and often humorous narration. The narrator finds herself unable to control her body, falling into the stereotype that has been forced on her.

Hasegawa Junko's Museiran is narrated by a thirty-something woman who dreams of becoming pregnant. She uses a rich mixture of kango, bikago, and feminine forms; her unique language develops a complicated character who feels that nobody knows the 'real' her.

'Feminine' and other gendered styles are used by the different Japanese authors in a variety of ways: in dialogue, to index social identity, to highlight the difference between the social and inner self, and different styles are mixed together for emphasis. Gendered styles, therefore, are central to the stories and translators wishing to adhere closely to the source text should pay close attention to this issue.

These stories encompass a great variety of language, gender, and translation issues, and should not be tied together into a false cohesion. However, one element that these stories do share is that the narrators demonstrate an understanding of 'social sanction and taboo'. Komugi in Miruku displays an uneasy attitude to language and social expectations; the narrator of Musuko no kuchibiru falls in with the stereotypes imposed on her, and Moriko in Museiran chastises herself for inappropriate behaviour for her age. These stories illustrate the way in which gendered language styles in Japanese can be manipulated in a self-conscious way as both the writers and the characters they create use different styles for effect.

I also argue that because English does not have a similar 'women's language' to Japanese, translation of 'feminine' or other gendered language can prove challenging. Musuko no kuchibiru, however, seems to be relatively unchallenging, as motherly and polite 'feminine' aspects of the narrator's voice have similar connotations of femininity in English. Translator of Museiran Philip Price enjoys the wordplay, but does not communicate the feminine nuances of certain phrases: as narrator Moriko's feminine styles have different connotations of nostalgia, irony and others, certain aspects of the story are not conveyed in his translation. 
.

The translation in this collection that most clearly conveys the gendered language of the source text is Louise Heal's 'Milk'. Heal adopts a voice that communicates the girlish, vulgar and slangy styles of the source text. Not all the stories feature such an identifiable figure as the confused teenaged girl in Miruku, so this method is not always applicable, but in this case Heal's use of an English-speaking equivalent of the Japanese narrator proves very effective. As case-by-case creative solutions such as Heal's appear to be the most successful, specific and widely applicable translation strategies for gendered styles are not identified. However, the analyses of these English translations again highlight the importance of the gendered language in the texts.

The issues of gender in Japanese fiction and English translation are multiple and multidisciplinary. Many aspects of this research would benefit from further exploration. A similar study of 'masculine' styles in writing by Japanese men, interesting in itself, could be compared with these findings. The scope of the research could be broadened, for example, to include writings from different eras, or to examine male narrators in works by female writers and vice versa. These issues could also be analysed in languages other than Japanese or English. In fact, the analysis of the connections between gender, language, literature, translation and society provides unlimited opportunities for research and new insights.

\section{References}

Abe, H., 'Stereotype to Context: The Study of Japanese Women’s Speech', Feminist Studies, 21.3 (1995), pp. 647-671.

Bassnett-McGuire, S., Translation Studies (London: Methuen, 1980).

Baumgarten, N., 'On the Women's Service?: Gender-conscious Language in Dubbed James Bond Movies', in Santaemilia, J. (ed.), Gender, Sex, and Translation: The Manipulation of Identities (Manchester: St. Jerome, 2005) pp. 5370 .

Buckley, S., 'Mobile Telephones', in Encyclopedia of Contemporary Japanese Culture (London: Routledge, 2002) pp. 328-329.

Butler, J., 'Performative Acts and Gender Constitution: An Essay in Phenomenology and Feminist Theory' in Conboy, K., Medina, N., and Stanbury, S. (eds.), Writing on the Body: Female Embodiment and Feminist Theory (New York: Columbia UP, 1997) pp. 401-418.

Cameron, D. and Kulick, D., Language and Sexuality (Cambridge: Cambridge UP, 2003).

Daidō, T., 'Miruku', Miruku (Tokyo: Chuokoron-shinsha, 2004) pp. 6-36.

Farnsley, K. W., 'Women and Language', Urbana, 13.2 (1995), pp. 1-8.

Fought, C. Interview. Do You Speak American? Episode 3. Writ. Cran, W., MacNeil, R. Dir. Cran, W. PBS, New York. 19 
January 2005.

Frederick, S., 'Not That Innocent: Yoshiya Nobuko's Good Girls', in Bardsley, J., Miller, L. (eds), Bad Girls of Japan (New York: Palgrave Macmillan, 2005) pp. 65-79.

Gare, S., 'Airheads', Lingua Franca, ABC Radio National, Melbourne. 3 February 2007.

Goddard, B., 'Theorizing Feminist Discourse/Translation' in Bassnett, S., Lefevere, A. (eds), Translation, History and Culture. (London and New York: Piter Publishers, 1990) pp. 87-96.

Hasegawa, J., 'Museiran', Hatsuga (Tokyo: Magazine House, 2004) pp. 105-142.

Heal, L. (trans.), 'Milk' by Daidō, T. in Layne, C. (ed), Inside and Other Short Fiction: Japanese Women by Japanese Women (Tokyo: Kodansha International, 2006) pp.13-42.

Ide, S., 'Japanese Sociolinguistics: Politeness and Women's Language', Lingua, 47 (1982), pp. 357-385.

Inoue, M., 'Speech without a speaking body: “Japanese women's language” in translation', Language and Communication, 23.3 (2003), pp. 315-330.

Inoue, M., Vicarious Language: Gender and Linguistic Modernity in Japan (Berkeley: California UP, 2006).

Kemp, A. C., 'Ask A.C: 818', Slang City. Retrieved 15 March 2007, from http://www.slangcity.com/ask_ac_archive/818.htm.

Layne, C., (trans). 'My Son's Lips' by Uchida, S., in Layne, C. (ed.), Inside and Other Short Fiction: Japanese Women by Japanese Women (Tokyo: Kodansha International, 2006) pp. 101-122.

Maynard, S., Expressive Japanese (Honolulu: Hawaii UP, 2005).

Okamoto, S., 'Ideology in Linguistic Practice and Analysis: Gender and Politeness in Japanese Revisited', in Okamoto, S., Shibamoto Smith, J. (eds.), Japanese Language, Gender and Ideology: Cultural Models and Real People (Oxford: Oxford UP, 2004) pp. 38-56.

Orbaugh, S., 'The Body in Contemporary Japanese Women's Fiction', in Schalow, G., Walker, J. A. (eds.), The Woman's Hand: Gender and Theory in Japanese Women's Writing (Stanford: Stanford UP, 1996) pp. 119-164.

Ozeki, R. 'Foreword', in Layne, C. (ed.), Inside and Other Short Fiction: Japanese Women by Japanese Women (Tokyo: Kodansha International, 2006) pp. 7-11.

Price, P. (trans), 'The Unfertilized Egg' by Hasegawa, J., in Layne, C. (ed.), Inside and Other Short Fiction: Japanese Women by Japanese Women (Tokyo: Kodansha International, 2006) pp. 171-202.

Santaemilia, J., 'Introduction', in Santaemilia, J. (ed.), Gender, Sex, and Translation : The Manipulation of Identities (Manchester: St. Jerome, 2005) pp. 1-8.

Shibamoto, J., 'The Womanly Woman: Manipulation of Stereotypical and Nonstereotypical Features of Japanese Female Speech' in Philips, S. U., Steele, S., Tanz, C. (eds.), Language, Gender and Sex (Cambridge: Cambridge UP, 1987) pp. 26-49.

Shibamoto, J., 'Women's Speech in Japan', in Tsujimura, N. (ed.), Japanese Linguistics (London: Routledge, 2005) pp. 181-190. 
New Voices Volume 2

Smith, J. S., 'Women in Charge: Politeness and Directives in the Speech of Japanese Women', Language in Society, 21 (1992), pp. 59-82.

Soanes, C. and Stevenson, A. (eds.), 'Cryptogam n.; 'Rafflesia n.', The Concise Oxford English Dictionary: Oxford Reference Online. Retrieved 18 September 2007, from http://www.oxfordreference.com/views/ENTRY.html

Tomioka, T., 'Women's Language and the National Language', Trans. Ericson, J.E., Nagaoka, Y., in Copeland, R., Woman Critiqued: Translated Essays on Japanese Women's Writing (Honolulu: Hawaii UP, 2006) pp. 135-144.

Uchida, S., 'Musuko no kuchibiru', Musuko no kuchibiru (Tokyo: Kadokawa, 2000). pp. 5-32.

Ueda, M., The Mother of Dreams: Portrayals of Women in Modern Japanese Fiction (Tokyo: Kodansha International, 1986).

Washi, R., “Japanese Female Speech” and Language Policy in the World War II Era', in Okamoto, S., Shibamoto Smith, J. (eds.), Japanese Language, Gender and Ideology: Cultural Models and Real People (Oxford: Oxford UP, 2004) pp. 76-91.

Yokota-Murakami, T., 'Female Gender and the Father's Abuse: On the Construction of Femininity in Contemporary Japanese Women's Writings', Proceedings of the Midwest Association for Japanese Literary Studies, 5 (1999), pp. 332-338 